\begin{tabular}{|c|c|c|c|c|}
\hline & Area searched & & No of larval samples & \\
\hline Year & $\left(\mathrm{km}^{2}\right)$ & C. hominivorax & Rate* & Others $\dagger$ \\
\hline 1977 & 773,000 & 51,128 & 6.61 & 2,224 \\
\hline 1978 & 878,990 & 43,097 & 4.90 & 1,828 \\
\hline 1979 & 899,000 & 16,252 & 1.81 & 1,443 \\
\hline 1980 & $1,056,650$ & 3,983 & 0.38 & 2,186 \\
\hline 1981 & $1,332,000$ & 11,712 & 0.88 & 1,903 \\
\hline 1982 & $1,332,000$ & 16,187 & 1.22 & 2,345 \\
\hline 1983 & $1,824,000$ & 5,658 & 0.31 & 3,228 \\
\hline 1984 & $1,825,660$ & 2,821 & 0.16 & 3,442 \\
\hline 1985 & $1,825,660$ & 1,580 & 0.09 & 2,794 \\
\hline
\end{tabular}

* Screwworm cases per $\mathrm{km}^{2} \times 100$

$\dagger$ Myiasis by other calliphorid fly species provides an index of sampling intensity.

the Yucatan was mainly due to the weather?

Readshaw suggests that undetected pockets of screwworms may exist. But the detectability of this highly mobile, colonizing species is particularly great due to the boom and bust patterns ${ }^{8}$ shown by its populations, and the damage it causes even at low densities. Undetected relic populations are thus unlikely to occur over seasonal periods.

Readshaw concludes by mentioning an outbreak in northeastern Mexico in 1985, tacitly suggesting that screwworms had not in fact been eradicated. But all 151 cases concerned were found in Tamaulipas and San Luis Potosi between 23 June and 10 August; all were discovered within $5 \mathrm{~km}$ of the main road despite searches by 102 livestock inspectors throughout the two states'; and it is suspected that the cases were due to the deliberate release of fertile pupae following the making of a large number of inspectors redundant in June. As of July 1986 no screwworms have been detected west or north of the Isthmus of Tehuantepec for a year ${ }^{10}$. We believe that this is eradication and that sterile male releases are primarily responsible.

The project is now in a position to plan with some confidence for the cost effective eradication of screwworm south to Panama ${ }^{11}$. It would be deplorable if the extraordinary achievements of this project should be doubted on the basis of a fallacious argument, especially as it may discourage other attempts to control or eliminate major pest populations.

E.S. KRAFSUR

Iowa State University,

Department of Entomology

Ames, Iowa 50011, USA

H. TOWNSON Liverpool School of Tropical Medicine Liverpool L3 $5 Q A, U K$

G. Davidson C.F. Curtis

London School of Hygiene and Tropical Medicine,

London, WCIE 7HT, UK

1. Readshaw, J.L. Nature 320, 407 - $410(1986)$

. Krafsur, E.S. Entomol. exp. appl.37, 297-305 (1985)

3. Meadows, M.E. Misc. Publ. Entomol. Soc, Am. 62, 8-11 (1985)

4. Graham, O.H. \& Hourrigan, J.L. J. med. Entomol. 13 $629-658(1977)$.
. Bushland, R.C. Misc. Publ. Entomol. Soc. Am. 62, 12-15 (1985).

6. Graham, O.H. Misc. Publ. Entomol. Soc. Am. $621-3$ (1985).

Pineda-Vargas, N. Misc. Publ. Entomol. Soc. Am. 62, $22-27(1985)$

8. Krafsur, E.S., Hightower, B.G. \& Leira, L. J. med. Entomol $16470-481$ (1979).

9. Weekly Screwworm Status Reports (APHIS, USDA Hyattsville, Maryland, 1985).

10. Hoelscher, C.E. Entomology Notes 26, Texas Agricultural Extension Service (1986).

. Snow, W.J., Whitten, C.J., Salina, A., Ferrer, J. \& Sudlow, W.H. J. med. Entomol. 22, 353-360 (1985).

\section{UK release of genetically marked virus}

SiR-While awaiting its full analysis, I should like to outline the recent experimental release by scientists from this institute of a genetically marked baculovirus in a 'cabbage-patch' ecosystem after consideration of the safety aspects and in consultation with relevant authorities. The parent virus, Autographa californica nuclear polyhedrosis virus (AcNPV), is a registered insecticide in the United States and has been the subject of extensive safety testing by the protocols of the US Environmental Protection Agency. Like other baculoviruses, AcNPV has many attributes that make it a desirable alternative to chemical insecticides; for example, the virus does not infect or harm vertebrates or plants or invertebrates, other than a limited number of moth pests. AcNPV has been used successfully for the agricultural control of caterpillar pests and has been shown not to have deleterious effects on beneficial or non-target insect (or other) species.

To genetically mark AcNPV, a noncoding synthetic oligonucleotide sequence (about 80 nucleotides long, with stop codons in all six reading frames and no ATG codons) was placed in an intergenic region of the viral genome at a position that deletion experiments have shown is non-regulatory and expendable. To make the marker harmless, its composition and place of insertion were such that it neither added to, nor detracted from, the coding or regulation of any viral gene product.

Prior to its release, the marked AcNPV was extensively tested in the laboratory with regard to its genetic stability and biological phenotype and in comparison with unmarked virus. The laboratory analyses included replication studies involving more than 50 generations in insect tissue culture (sequential plaque assays) and successive passaging in caterpillars. By sequencing and other analyses no genetic instability of the virus, or marker, was detected. Titration of cloned marked and unmarked viruses in more than 70 species of UK Lepidoptera and selected Hymenoptera failed to identify differences in infectivity (susceptibility or 50 per cent lethal dose titres) or any other change in biological phenotype, and show that the cloned viruses have a highly restricted host range among UK moth species.

After evaluation of the data and in consultation with relevant agencies (UK Advisory Committee on Genetic Manipulation, Nature Conservancy Council, Ministry of Agriculture, Fisheries and Food, Department of the Environment) authority was given for a limited release of caterpillars of Spodoptera exigua (small mottled willow moth) preinfected with the marked virus. The release was undertaken in a field facility consisting of a netted compound which prevented dispersal of the host or its interaction with other insects or predators, thereby restricting dispersal and the opportunity for viral amplification and interaction.

The ecological object of the study was to measure precisely the ability of the virus to persist in the ecosystem under study. Analyses of persistence involved laboratory assays of virus on foliage and soil. These, plus the evidence for genetic stability, and restricted spread in natura, will be reported when the data have been analysed. The overall purpose of the project was to develop a risk assessment case study on the use of genetically engineered agents in the environment. This particular study concerned baculovirus insecticides, of which there is considerable practical experience and evidence concerning safety. As baculoviruses are not free-living agents, have a restricted host range and a good record of use in the environment, they have many advantages for such studies.

The long-term goal of this programme is to make custom-designed viral insecticides that, unlike broad-spectrum chemicals, are specific and limited in their host range as well as limited in their ability to persist or to have ecological impact. Since these studies represent a new era of environmental research, we believe that it is essential that a cautious developmental approach is used involving controlled field experiments that are preceded by extensive laboratory analyses. This approach will allow assessment of risk and environmental consequences to be made in a systematic manner and permit the testing of predictions concerning ecological impact.

Natural Environment Research DAVID H.L. BISHOP

Council Institute of Virology Mansfield Road, Oxford OXI 3SR, UK 